\title{
ADICIONES AL «DICCIONARIO DE LINGÜÍSTICA DE LA ESCUELA ESPAÑOLA» Y OTRAS NOTAS SOBRE LA ESCUELA PIDALINA
}

FRANCISCO ABAD

UNED. Madrid fabad@flog.uned.es

\section{RESUMEN}

Estas Notas añaden al Dicrionario de lingüistica de la escuela española los conceptos presentes en la Historia de la lengua española de Menéndez Pidal. y dan noticias inéditas del "Centro de Estudios I listóricos" durante la guerra (1936-1939) y del papel de Dámaso Alonso en los origenes de la expresión generación del 2?.

Palabras Clave: Menéndez Pidal: Rafael Lapesa: «generación del 27».

\section{RÉSUMÉ}

Ces Votes ajoutent au Diccionario de lingüustica de la escuela española les notions contenues dans llistoria de la lengua espanola de Menéndez Pidal et apportent des renseigments inédits sur le "Centro de Estudios Históricos" pendant la guerra civile espagnole (19:36-19:39). et du rôle joué par Dámaso Alonso dans les origines de l'expression generación del 27 .

Mots CleF: Menéndez Pidal; Rafael Lapesa; «generación del 27».

\section{AdiCIONES AL «DicCionaRIo DE LINGǗSTICA DE LA ESCUELA ESPAÑOLA»}

La publicación de varios escritos póstumos de don Ramón Menéndez Pidal, y en particular de su Historia de la lengua española (2005), hace que tengamos que añadir al- 
gunas entradas o textos pertinentes a nuestro Diccionario... (1986, ultimado en 1984). Sistematizamos lo que de interés más conceptual y general nos parece haber encontrado en esa Historia... del maestro.

Aljamía, La. Menéndez Pidal entiende por ella la lengua vulgar romance de al-Andalus. «Sin duda - escribe- en los primeros siglos de dominación musulmana el pueblo de al-Andalus hablaba predominantemente en aljamía, en la lengua romance heredada de sus antecesores hispano-romanos o hispano-godos, pues esta población seguía siendo mayoritaria frente a los colonizadores beréberes, árabes o sirios»; se daba así una preponderancia de muladíes y mozárabes aljamiados.

Bibliografía. R. Menéndez Pidal, Historia de la lengua española, I.

Analítica y analógica en la evolución del idioma, Tendencias. Teoriza nuestro autor: «Al convertir el lenguaje una forma sintética antigua en una analítica, busca mayor viveza en la expresión. Cuando el futuro latino [...] se expresó perifrásticamente [...] se significó más enérgicamente que el simple futuro, la necesidad de lo venidero, aunque luego paró en significar sólo lo venidero [...]. También se reforman las palabras para aclarar su categoría gramatical, haciendo resaltar su analogía con la generalidad de su clase. El anticuado la señor tomó la - a característica de la mayoría de los femeninos, la señora».

Bibliografía. Historia de la lengua..., II.

Andalucismo del español americano. Añádase ${ }^{1}:$ «Hay que volver a la más moderada posición de R. J. Cuervo, quien [...insistió] de continuo en el hecho de que todas las comarcas de la Península Ibérica contribuyeron con sus habitantes y con sus provincialismos a la población y al habla del Nuevo Mundo, de modo que a la vez que se conservan en América expresiones andaluzas, existen otras aragonesas y catalanas o bien asturianas, gallegas y portuguesas. La totalidad del idioma español contribuye al trasplante, dice Cuervo [...]. Apenas puede hablarse de otra cosa [que de un continuado influjo de la metrópoli] tratándose de una lengua colonial incipiente y una lengua metropolitana en plena edad de oro literaria y en el apogeo de su fuerza expansiva política y cultural. [...] Hecha toda clase de salvedades, no puedo menos de volver a la vieja opinión andalucista entendida como lo hizo R. J. Cuervo» (Menéndez Pidal).

Bibliografía. R. Menéndez Pidal, Historia de la lengua española, I.

Buen uso. Define el propio don Ramón: «El acatamiento general ganado por el habla de los grupos sociales más prestigiosos en los varios órdenes de la vida, constituye el «buen uso», apoyado por los modelos de la literatura y por las enseñanzas de los gramáticos. Así se establece en la práctica todo un código de normas de bien decir, y la estimación social castiga al contraventor de esas normas con una nota de menos valía».

Bibliografía. R. Menéndez Pidal, Historia de la lengua española, II.

' Añádase -evidentemente- a lo que hemos recogido ya en F. Abad, Diccionario de lingüística de la escuela española, Madrid, Gredos, 1986. en la entrada correspondiente. 
Cambio lingǘstico, Proceso del. Añádase: «La difusión de cualquier corriente neológica destinada al triunfo tiene su punto de partida en una pequeña minoría que se acredita como modelo distinguido; el progreso del fenómeno invasor es efecto de una prevalencia cultural y no numérica» (Menéndez Pidal).

Bibliografía. R. Menéndez Pidal, Historia de la lengua española, I

Consonantismo castellano, Procesos en la evolución del. «Las dos tendencias opuestas —escribe en uno de los momentos en que se ocupa del asunto Menéndez Pidal-, la de relajación articulatoria que constante y normalmente actúa en el lenguaje, y la de $r e$ fuerzo articulatorio, que es poco frecuente por su carácter expresivista, venían trabajando desde los orígenes del idioma una, y desde hacía mucho tiempo la otra, pero sólo llegan a generalizarse e invadir la lengua literaria durante el siglo XvI, merced a la doctrina estética dominante entonces que equiparaba la lengua escrita y la popular o natural». Asimismo ilustra cómo «el caso principal [de refuerzo fonético] que puede citarse en la fonética regular, es el refuerzo expresivista de la vocal acentuada latina ě y ó en los diptongos crecientes ié y ué $[\ldots]$, caso tan general y abundante como el contrario de debilitación de los diptongos decrecientes latinos que se monoptongan ( $\mathrm{a}$ u $\mathrm{r} \mathrm{u}>$ toro, I a i c u > lego)».

Bibliografía. R. Menéndez Pidal, Historia de la lengua española, I y II.

«Cuña lingüística castellana». Don Ramón hizo suya esta imagen sobre la que ahora manifiesta: «Castilla se hace, poco a poco, centro político de una nueva España. Paralelamente a ese creciente relieve de Castilla en el imperio leonés, con la progresiva castellanización del reino de Toledo, la cuña linguística castellana empieza a hender y separar la unidad de la lengua común primitiva para crear la lengua común moderna».

Bibliografía. R. Menéndez Pidal, Historia de la lengua española, I.

Escrita, Lengua. Añádase: «"El habla escrita” es un acto perdurable que se dirige no a un oyente inmediato, sino a un lector por lo general desconocido, actual o futuro. El paso de la forma oral a la escrita provoca en el sujeto, cualquiera que sea su condición social, un afán de superación, un esfuerzo deliberado por incorporarse al ambiente cultural común. Fundamentalmente exige un trabajo de estudio y corrección para eliminar del habla espontánea la rapidez o la lentitud ocasionales del momento, y lograr la precisión que reclama la lectura, acto de atención más tensa, comparado a la audición, acto de percepción más pasiva. Aun en una carta privada, el solo hecho de poner la pluma sobre el papel impone al hablante la necesidad de una elaboración del lenguaje muy superior a la usual en el habla cotidiana. [... La lengua escrita] siempre se distingue de la hablada por el artificio y mayor compostura» (Menéndez Pidal).

Bibliografía. R. Menéndez Pidal, Historia de la lengua española, II.

Épocas de la historia del español. Añádase la distinción pidalina del «español primitivo» (el cual "por el escaso número de cultivadores y sobre todo por la escasez de textos conservados no se presta a observación alguna»), el «español antiguo», el «español clásico» y el «español moderno». «El idioma —concreta nuestro autor respecto de la época 1474-1516 - sufre ahora en sus rumbos el giro más amplio y fuerte que en mil años de vida ha experimentado", cambio de rumbo debido a la unificación 
definitiva de los dos grandes dialectos afines castellano y aragonés; a la aparición de la imprenta en la Península, el organismo que más hizo por uniformar la lengua literaria; a «los descubrimientos geográficos, la dispersión de los judíos españoles, las empresas de Italia»; etc.

En tanto criterio general de la periodización lingüística mantiene nuestro autor esta doble opción: «Establezco periodos breves, de veinte a cuarenta años por lo común, duración que da claridad al desarrollo del continuo histórico. Atiendo en ellos a las principales corrientes de la estilística personal, única que tiene una duración precisa [...]. La lengua común hablada, poco documentada y de cronología muy vaga, varía menos que la lengua literaria, por lo cual sólo expongo sus mudanzas en periodos más largos que engloban varios de la lengua artística».

Bibliografía. R. Menéndez Pidal, Historia de la lengua española, I y II.

Evolución del lenguaje y voluntad de los hablantes. Añádase y matícese con este pasaje de don Ramón: «Los sucesos históricos, una evolución en las instituciones políticas o religiosas de un pueblo, una clase superior que pierde el poder, una guerra, una expansión comercial o cualquier otro, arrastran consigo alguna novedad en el lenguaje, mas por lo común sólo en el vocabulario. La difusión colonizadora de un pueblo trae algún desequilibrio entre el lenguaje colonial y el metropolitano: por una parte el lenguaje colonial es arcaizante [...]; por otra parte, al mudar de ambiente o mundo circundante y al propagarse a otras razas mestizándose con otras tradiciones lingüísticas, debilita su propia tradición».

Bibliografía. R. Menéndez Pidal, Historia de la lengua española, II.

Historia literaria e Historia lingüística. Menéndez Pidal proclama: «Tampoco podemos hoy pensar [...] como el positivismo, que en el estudio de un idioma la literatura interese sólo como medio para conocer el uso linguiístico. El lenguaje se modela por los artistas del hablar, escritores o ágrafos, y siempre los escritores realizarán la manifestación más alta del lenguaje, por lo cual no concebimos la historia linguística sino en esencial unión con la historia literaria».

Bibliografía. R. Menéndez Pidal, Historia de la lengua española, II.

«Imitación». «Con Garcilaso —estima y subraya nuestro autor- comienza la literatura a aplicar habitualmente la teoría renacentista de la imitación, concepto técnico que tuvo su importancia en el desarrollo del lenguaje de la época. El subrogar las emociones de la vida actual por las emociones descritas en los autores clásicos, según hacían los mejores poetas de la época anterior, se sustituye ahora por una más íntima y fecunda inspiración en aquellos autores».

Bibliografía. R. Menéndez Pidal, Historia de la lengua española, I.

Lengua, varias clases de. Distingue don Ramón: «Un idioma dado no es un todo uniforme, sino que ofrece variedades que importa diferenciar bien. Según el ámbito geográfico que cada uno de los tipos del idioma alcanza, se distingue una lengua común, la de ámbito más extenso, la más general, a diferencia de las lenguas dialectales, que viven dentro del territorio de la lengua común y emplean formas fonéticas, morfológicas y sin- 
tácticas diversas de las comunes, aunque afines a ellas. Hay también lenguas locales o provinciales, que simplemente usan algunos vocablos de uso local y acaso una pronunciación en algo distinta de la común. Además dentro de un mismo ámbito geográfico hay agrupaciones particulares de hablantes, unidos por algún modo de vida común que les impone el uso de ciertos vocablos y expresiones peculiares. Así hay lengua profesional o técnica, lengua de una clase social dada, lengua familiar; hay jerga estudiantil, de germanía, soldadesca, etc. [...] La lengua común, formada mediante la exclusión o la parcial asimilación de los particularismos, se elabora en la conversación, en los negocios, en la literatura, por la selección de hablantes que viven las actividades superiores de la comunidad y participan de la más alta cultura; se fragua en las mayores ciudades, que son las menos apegadas a sus localismos propios, porque a ellas concurren gentes de todas partes, y suelen los forasteros ser los dirigentes; se propaga en todas direcciones por los caminos del comercio vital que parten de esos mayores centros urbanos». Cfr. además la entrada del Diccionario de lingüística..., Dialectal, El lenguaje como complejidad.

Bibliografía. R. Menéndez Pidal, Historia de la lengua española, II.

Lengua literaria, Historia de la. Añádase: «Como acto artístico perdurable, tendiendo a una expresión que sirva para todos y para todo, [la lengua literaria] prefiere las formas lingüísticas de mayor ámbito de comprensibilidad, las de mayor arraigo en el idioma, las más nobles, las que menos han rodado en el habla vulgar y menos se han contaminado en los empleos bajos de la vida, las que se hallan consagradas en las más hermosas realizaciones que la lengua ha tenido bajo la pluma de los escritores antepasados. [...] La lengua literaria puede ir informada por un propósito principalmente estético o por uno utilitario, y será poética o prosaica. Por sus caracteres rítmicos puede ser versificada o prosística, y claro es que una obra versificada puede ser prosaica y una obra prosística puede ser poética. El habla poética por su liricidad, por su vibración emocional, realiza el mayor esfuerzo de invención o subjetividad creadora».

Establece asimismo don Ramón la periodicidad en la alternativa de los estilos que él llama respectivamente de naturalidad y de artificiosidad: «Aunque los dos temperamentos expresivos convivan siempre, no obstante en las corrientes literarias colectivas domina el uno o el otro según los tiempos. De una parte naturalidad, selección, conservatismo, neologismo conceptual y práctico, clasicismo, y de otra parte artificiosidad, invención, neologismo de estilística personal, barroquismo, producen acciones y reacciones alternativas, cuya sucesión nos explica simplificadamente la historia de la lengua literaria».

Bibliografía. R. Menéndez Pidal, Historia de la lengua española, II.

Limites lingüísticos. Las mismas ideas que ya conocemos en esta entrada del Diccionario..., las da Pidal en el $\$ 3$ de las pp. 492-493 de la Historia..., I.

Bibliografía. R. Menéndez Pidal, Historia de la lengua española, I.

Mediterránea, Unidad lingǘstica. Es tesis pidalina la de que «la multitud de pueblos que habitaban alrededor del Mediterráneo tuvo una primigenia unidad de lengua, como los indoeuropeos tuvieron la suya; unidad [...que] dejó rastros abundantes en los 
nombres de lugar iguales que hallamos esparcidos por todas las tierras del mar interno, desde el Asia Menor hasta España». En efecto esas semejanzas de nombres «pueden tomarse como residuos de un prehistórico e íntimo parentesco de idiomas entre los antecesores de los pueblos esparcidos y diversificados luego por toda la cuenca del Mediterráneo antes de la llegada de los indoeuropeos».

Bibliografía. R. Menéndez Pidal, Historia de la lengua española, I.

Siglo de la artificiosidad. La centuria del XVII es llamada así por don Ramón, quien además de subrayar que estamos ante una reacción contra el clasicismo renacentista, explica que entre las causas de esa reacción de artificiosidad se encuentran «la importancia concedida al perfeccionamiento de la forma artística; el considerar las lenguas románicas como latín "corrompido", que tanto se mejorarían cuanto más se amoldasen a la latinidad; el principio de la "imitación" de los autores latinos y griegos y su aplicación preferente a la epigramática alejandrina y de Marcial [...]; la decadencia del petrarquismo, con gran desarrollo de elementos conceptistas, etc.».

Bibliografía. R. Menéndez Pidal, Historia de la lengua española, 1

Sincretismo. Entiende don Ramón por sincretismo la 'coexistencia de formas', y así en referencia a los siglos x y XI escribe: «El carácter más distintivo de la lengua escrita es su enorme indecisión $[, y]$ esta falta de fijeza responde en buena parte a que en el caudal linguístico de los hablantes sobreviven múltiples capas de arcaísmo que van, a veces, desde la pura forma latina y la románica muy antigua hasta otras románicas recientes, más o menos innovadoras».

Bibliografía. R. Menéndez Pidal, Historia de la lengua española, I.

\section{Registro de fuentes}

Ramón Menéndez Pidal, Historia de la lengua española, Madrid, Fundación Ramón Menéndez Pidal y Real Academia Española, año dos mil cinco, dos vols.

Cfr. F. Abad, Diccionario de lingüística de la escuela española Madrid, Gredos, 1986.

II. El «CEnTRo de Estudios Históricos» DURANTE LA GUERRA:

LA OBRA CÍVICA Y HUMANITARIA DE RAFAEL LAPESA

\section{Una noticia del «Centro» en 1936/1938}

Un joven Rafael Lapesa que casi acababa de cumplir 31 años, hubo de responder por escrito el 14 de Abril de 1939 al ínterrogatorio al que se refería el Decreto de 21 de Enero de ese mismo año dado por los vencedores de la guerra civil; se trataba de que tal declaración jurada surtiese sus efectos en el expediente de depuración al que -se entiende- estaba sometido nuestro estudioso. El Ministro de Educación Nacional era entonces - lo fue hasta el 9 de Agosto de ese año-Pedro Sáinz Rodríguez. 
Con la necesaria capacidad de comprensión histórica, debemos hacer un esfuerzo por imaginar con verosimilitud las circunstancias generales europeas y españolas de los años treinta, y en particular las circunstancias muy adversas en que alguien vinculado a Menéndez Pidal, a Américo Castro, y a la «Junta para Ampliación de Estudios». tenla que ser visto dada la nueva situación, y por entender asimismo las limitaciones contextuales con que debía producirse la literalidad de las respuestas, con fórmulas hechas prácticamente obligadas, mucha prudencia, etc. Lapesa estaba —al igual que sus maestros mencionados - entre los vencidos de la guerra, aunque en ella desempeñó una labor humanitaria y también cívica de salvamento del patrimonio histórico.

«No he pertenecido nunca - manifestaba el joven Rafael el aludido día 14 de abril - a ningún partido político. En dos ocasiones he rehusado [...] ingresar en el Partido Comunista [...] Me negué diciendo que como católico, no podio ser marxista»; este dato vivencial fue repetido luego por Lapesa alguna vez: nosotros mismos se lo oímos en conversación en su casa con él y con Joaquín Pérez Villanueva ${ }^{2}$. «Como perteneciente al reemplazo de 1929, fui movilizado por llamamiento de quintas en 1 de marzo de 1938. [...] Sólo he sido soldado y no he hecho servicio de armas».

A la pregunta de si habla residido «en población dominada por el enemigo», él -que había pasado la guerra en Madrid - respondió: «Me ha retenido en la zona roja la necesidad ineludible de ayudar económicamente a familiares que habían quedado cesantes o sin trabajo y que carecían de recursos».

La noticia que da el joven Rafael acerca del «Centro de Estudios Históricos» posee todo interés documental, aun en abreviatura:

Fui encargado de dicho Centro en Madrid desde 27 de enero de 1937 hasta octubre de 1938. [...] El 18 de Agosto [de 1936] hubo un asalto perpetrado por catedráticos de Instituto ajenos al Centro y resentidos contra él. Con el pretexto de que la Junta para Ampliación de Estudios no había sido depurada de elementos derechistas, los asaltantes intentaron incautarse de ella, lo que impidió el entonces ministro Sr. [Francisco] Barnés [...]. Basándose en la conveniencia de que la Junta apareciera controlada por elementos adictos a la situación, se constituyó poco después un «Frente Popular de la Junta para Ampliación de Estudios» presidido por el profesor italiano Giuliano Bonfante [...] Por iniciativa mía un miembro del Frente Popular de la Junta, D José Castro Escudero, gestionó del Batallón «Félix Bárcena» que algunos componentes de su compañía de reserva se encargaran de la custodia ( $\sin$ armas) y conservación del Centro, a fin de evitar que entraran allí evacuados o milicias. En el grupo designado figuraba el que suscribe, juntamente con otros profesores y artistas. Nuestro servicio comenzó el 9 de Diciembre. [...] Trasladado el Ministerio a Valencia, se formó una Comisión Delegada de la Junta para Ampliación de Estudios, cuyo Secretario fue Don Tomás Navarro Tomás [... La Comisión Delegada] me nombró el 27 de Enero «para que esté al frente del Centro de Estudios Históricos, atienda al cuidado del mismo, mantenga la relación necesaria con los colaboradores que trabajan en Valencia y resuelva las dificultades que en cualquier momento se puedan presentar». [...] No pasé de ser - ni hubiera aceptado otra cosa- un encargado o Secretario, pues a partir de la marcha de D. Ramón Menéndez Pidal la Dirección fue asumida por la Comisión Delegada, especialmente por el Sr. Navarro Tomás. [...] La épo-

${ }^{2}$ El presente trabajo responde a una búsqueda de archivo, más a charlas con el propio don Rafael y con Joaquín Pérez Villanueva en casa del primero. Damos las gracias por su ayuda necesaria al prof. Olegario Negrîn Fajardo, quien en definitiva nos facilitó los documentos. 
ca más difícil para mí comenzó en el otoño de 1937. Hasta entonces todos los colaboradores que quisieron seguir sus estudios en el Centro encontraron toda clase de facilidades, e incluso permití trabajaran en él personas que antes no colaboraban. Sabiendo que había entre unos y otros derechistas y perseguidos, veía satisfecho cómo encontraban en el Centro un refugio espiritual, y tuve la alegría de proporcionarles certificado de trabajo, aunque frecuentaran el Centro para estudios particulares. Pero al venir a Madrid como Delegado del Ministerio el Sr. Naval, dio una serie de órdenes persecutorias [...] En octubre de 1938 la Comisión, accediendo a peticiones mías muy anteriores, nombró Director accidental del Centro en Madrid a D. Benito Sánchez Alonso?.

En tanto garantes de la veracidad de sus manifestaciones Lapesa acompañó a su Declaración del 14 de Abril de 1939 varios testimonios, uno de ellos de quien en esa fecha era canónigo de Las Palmas D. Deogracias Rodríguez Pérez, el cual en efecto hizo constar que aunque no se conocían previamente, sólo recibió de Lapesa «consideraciones y muestras de atención» mientras era encargado del «Centro»; añadió además: «Oportunamente me extendió certificado de trabajo y me lo renovó cuantas veces fue preciso, en la forma que se juzgaba mas conveniente para evitarme molestias», y expresaba: «Muchos de los elementos de derecha que quedábamos en el Centro [...] nos sentíamos amparados por su actuación».

Una carta anterior de nuestro estudioso a su maestro Menéndez Pidal de 19 de Mayo de 1937, le recordaba alguna cosa y le traía asimismo nuevas noticias del «Centro de Estudios Históricos», y entonces se manifestó en estos términos ${ }^{4}$ :

[El Centro] no ha sufrido daño ni en el edificio ni en las personas, salvo lo ocurrido al pobre Benito [fusilado por milicianos al tratar de proteger a un pariente perseguido], desgracia que Vd. ya conoce y que fue imposible evitar. En Madrid, después de una temporada de intemupción absoluta de los trabajos (noviembre-enero), durante la cual el Centro estuvo custodiado por una guardia de la Federación de Trabajadores de la Enseñanza, se van reanudando las tareas. Navarro me nombró para que me ocupase de las cuestiones administrativas y estuviese en relación con Valencia y con las imprentas, pues en Valencia parece imposible sacar las revistas, y el Ministerio no quiere que se interrumpa la publicación de ellas. [...] Desde luego, el Centro esta muy parado. Vamos todas las mañanas Crescente, [...]; y de Filología, sólo yo. No he dejado de la mano la Crestomatía. Terminé el estudio de la época de Mio Cid, aunque necesito ver documentos de Aragón, Occidente de León, y, si los hay, de Segovia y Ávila. Después lo he suspendido, pues me encargó Navarro un manualito de Historia de la lengua, nominalmente para obreros y campesinos, aunque en realidad me figuro que la materia no es demasiado apropiada para ese fin, y me daria por contento con que sirviera para maestros y bachilleres, aunque procuro hacerlo asequible a mentalidades despiertas, como las de tantos obreros inteligentes y con afán de cultura como hay. En diciembre, cuando los brutales bombardeos

3 Más de cuarenta años más tarde don Rafael evocaba así algunos de estos hechos: «Logré que a un grupo de colaboradores de la Junta y profesores del Instituto Escuela, movilizados todos para servicios auxiliares, se nos encomendase proteger los locales de Medinaceli, 4. Bajamos a los sótanos los ficheros, originales y demás documentación, y establecimos un tumo para con las armas de la palabra, pues no teníamos otras, salir al paso de posibles allanamientos» («Menéndez Pidal, creador de escuela: el Centro de Estudios Históricos», en el librito de Homenaje a Menéndez Pidal ;Alça la voz, pregonero!, Madrid, Cátedra-Seminario Menéndez Pidal, 1979, pp. 43-79: p. 76).

4 Hay reproducción fotográfica del original de esa carta en el librito Glosario del primitivo léxico ibero-románico. Proyecto de informatización, Madrid, Fundación Ramón Menéndez Pidal, 1998, pp. 21-24. 
de la aviación suponían un riesgo para los trabajos del Centro, recogí, ayudado por Vallelado [que colaboraba en el $A L P I]$ y Rodríguez Castellano unas veces, y otras por los de la FETE, todos los ficheros y originales que corrían más peligro; están en los sótanos, y los más interesantes, en una caja blindada. Me permití entrar en el despacho de V. y sacar de los armarios de la estantería todos los materiales que V. tenía allí. Con lo que no me atreví fue con los libros y papeles que estaban sobre la mesa, en espera de hacerlo con quien Vindicara [...] Claro está que en estas condiciones se puede trabajar bastante mal. El Glosario de Orígenes, con los ficheros abajo y la biblioteca casi cerrada, no puede seguir adelante $[. .$.$] ¡Ojalá pueda V. re-$ nunciar a su curso de Columbia y al otoño estemos trabajando como antes! [...] Le escribo a vuela pluma, todo revuelto, pero así tendrá V. noticias detalladas de su Centro, que tanto le echa de menos [...]. Desde luego, D. Ramón, disponga de mí para cualquier cosa que se le ocurra respecto a su casa de Chamartín o en cualquier otra gestión. Todo cuanto me pueda encargar, lo haré gustoso.

Esta carta escrita «a vuela pluma» nos da un testimonio exacto y vivencial del "Centro de Estudios Históricos» a fines de 1936 y en la primera mitad del año siguiente; vemos por ej. a Lapesa preparar su Historia de la lengua española, que hemos encontrado se anunció en efecto como obra «en preparación» en la «Biblioteca popular de cultura y técnica» de la Editorial Nuestro Pueblo, colección en la que llegó a publicar realmente Samuel Gili Gaya ${ }^{5}$.

En el inmediato 17 de Junio del mismo año 37 fue don Ramón quien compartía a su vez recuerdos y vivencias con Lapesa, y le decía: «Las últimas semanas que yo residí en Madrid el aspecto de Medinaceli, 4, no podía ser más triste, el 10 de diciembre, me parece, o el 11 , fui allí por última vez; todo estaba cerrado al exterior y oscuro al interior. La sombra del pobre Benito vagaba por aquellos pasillos sin luz» ${ }^{6}$.

\section{El expediente de depuración a Rafael Lapesa}

En 5 de Enero de 1940 la Comisión Depuradora C) de Madrid formuló sin embargo varios cargos en contra de Lapesa, a saber:

a) «Haber sido siempre simpatizante del Partido Socialista».

b) «Haber mantenido estrechas relaciones con destacados elementos revolucionarios, v. gr. como Américo Castro».

c) «Haber trabajado durante el periodo rojo en Madrid por mantener la actividad cultural del Centro de Estudios Históricos, facilitando al extranjero un buen argumento de la falsa apariencia de orden y buena marcha del régimen marxista».

\footnotetext{
'Tenemos - por haberla adquirido en librería de viejo- su Iniciación en la historia literaria española.

- Carta transcrita por Joaquín Pérez Villanueva, Ramón Menéndez Pidal. Su vida y su tiempo, Madrid, Espasa-Calpe, 1991. p. 352.

Don Ramón salió de Madrid el 14 de Diciembre: «emprendía - ha glosado Diego Catalán- lo que él creyó ser un breve "exilio" con el pretex to ofjcial de difundir los resultados de sus últimas investigaciones, tanto sobre la "Historia de la lengua española", como sobre "Epopeya y Romancero"»; vid. Diego Catalán El archivo del romancerol, $]$ patrimonio de la humanidad, Madrid, Fundación Ramón Menéndez Pidal, MMI, p. 184.
} 
Ante tal pliego de cargos, la declaración de descargo se produjo con fecha de 15 de Enero siguiente, y en ella manifestaba nuestro estudioso:

a) «Nunca he podido admitir el materialismo histórico socialista ni sus consecuencias prácticas. He anhelado la justicia social y la mejora de los humildes; pero mediante una legislación sabia, inspirada en la caridad cristiana y no en el odio promovedor de la lucha de clases».

b) «He tenido con Américo Castro relaciones derivadas de haber sido discípulo suyo. Pero ni en el trato profesional, ni en la amistad que de él nació, intervino jamás el factor político».

c) «Para mí era una necesidad imprescindible la de permanecer en Madrid, ya que habiendo quedado cesantes y perseguidos varios familiares míos muy allegados, tenía que reducir al mínimo mis gastos para ayudarles en cuanto pudiera. [Además, móvil de la permanencia en Madrid fue] impedir que el local del Centro de Estudios Históricos estuviera a merced del primer intento de ocupación por evacuados o milicias, con el consiguiente daño para los abundantes materiales científicos reunidos allí en muchos años de trabajo. [...] Salvé originales, ficheros, libros y mobiliario; escondí cuatro códices valiosísimos que, procedentes de la Academia de la Historia, encontré en los despachos. De todo hice entrega a los Sres. Herrero y Entrambasaguas cuando se posesionaron del Centro en nombre del Instituto de España. Ambos alabaron la labor de conservación realizada. [... Otro motivo de la permanencia en Madrid fue el de] ayudar en lo posible a colaboradores del Centro y otras personas que se hallaban sin documentación o perseguidas. Tan pronto como recibí el nombramiento de encargado del Centro, lo aproveché con estos fines».

El mismo 15 de Enero de la anterior declaración de descargo, Joaquín de Entrambasaguas - por otra parte adversario personal de don Ramón y su familia y de toda la escuela pidalina. según se ve en varios escritos suyos ${ }^{7}$-, facilitó a Lapesa certificación escrita de que «le tiene por persona honorable», y de que «durante la época roja se dedicó a salvar cuanto pudo del material científico existente en el Centro de Estudios Históricos». Asimismo certificaba que «el Sr. Lapesa le hizo entrega al liberarse Madrid de todo cuanto había[,] sin que faltara absolutamente nada».

El 24 de Febrero del mismo 1940 hizo una declaración jurada ante el Ministerio de Educación Nacional el relevante geógrafo Manuel de Terán, entonces de 35 años, quien manifestó en referencia a su compañero de Instituto: «Tengo la convicción de que es católico practicante, y en cuanto a ideología política lo tiene mas bien como persona $[\ldots]$ de tendencia conservadora, sin haber oído nunca ni aún a personas que en otros aspectos han emitido juicios desfavorables a él que haya pertenecido al partido socialista. [... Sabe por referencias que facilitaba certificado de trabajo [en el "Centro"] a las personas de derechas que estaban sin documentación». Testimonio tan honorable como el de Terán, aseguraba pues la imagen de sí mismo dada por Lapesa.

${ }^{7}$ Cfr. Ios textos verdaderamente injuriosos Pérdida de la Universidad española, Bilbao, Imprenta Palomeque, MCMXXXVIII; «Entre el padre y el hijo», Revista de Literatura, I, 1952, pp. 411-418. 
Menos de dos meses más tarde, el 13 de Abril, la Comisión Depuradora C) de Madrid consideró que resultaba que «en los años precedentes al Glorioso Movimiento Nacional [el catedrático de segunda enseñanza Rafael Lapesa] fue hombre destacado entre los elementos izquierdistas" y "persona de confianza del llamado Gobierno de Negrín», y así propuso por unanimidad «el traslado fuera de la provincia, inhabilitación para cargos directivos y de confianza y postergación de cinco años». Entre los cinco firmantes de la propuesta se encuentra «M. Herrero», que verosímilmente debía de ser el estudioso de la literatura años antes también vinculado al «Centro" Miguel Herrero García, quien al parecer había alabado sin embargo - según queda visto- la tarea de conservación de los locales y materiales de ese Centro desarrollada por Lapesa durante la guerra civil.

El acuerdo de la Comisión C) fue elevado a firme, y así la resolución del expediente de depuración se hizo Orden de 12 Julio de 1940 (era entonces Ministro de Educación Nacional José Ibáñez Martín), y quedó publicada en el Boletín Oficial del 13 de Agosto de 1940; el 2 de Octubre Lapesa se dirigió al Ministro de Educación y solicitó revisión de expediente por no creerse «merecedor de la sanción».

Ahora en este Octubre acompañaba - según había hecho ya en sus dos declaraciones exculpatorias anteriores (recordamos: 14 de Abril de 1939 y 15 de Enero de 1940)nuevos informes en defensa de su actuación. Una página de Dámaso Alonso fechada en Madrid días antes del aludido 2 de Octubre de 1940 decía a la letra declarar

que conoce desde hace muchos años a don Rafael Lapesa Melgar. y que le ha tenido siempre por persona de orden y católico. Que esto último le consta por declaración expresa y repetida de dicho Sr. Lapesa [...]. Que considera al Sr. Lapesa como una de las máximas autoridades en Lingüística española y elemento científico al que se deben dar toda clase de facilidades y estímulos para trabajar en las tareas culturales de nuestra patria. En fin, que es un hombre excepcionalmente dotado y absolutamente útil y digno.

Simultáneamente Benito Sánchez Alonso manifestaba que Lapesa «favoreció con certificados de trabajo a los que podían ser perseguidos por sus ideas [...y] puso siempre el mayor empeño en sostener la actividad del Centro [de Estudios Históricos]».

A la vez se producía asimismo un tercer escrito, esta vez del entonces Inspector $\mathrm{Ge}$ neral de Museos Arqueológicos Joaquín María de Navascués, quien ofreció este testimonio en referencia a la labor de nuestro estudioso:

Concretamente al declarante le facilitó un certificado de trabajo [...] durante algunos meses, hasta que el declarante pudo obtenerlo de otra persona y eximir del compromiso grave que contraía al (sic) Sr. Lapesa. [...] Obtuvieron análogo trato otras personas, entre ellas algún sacerdote. [...] Por conversaciones sobre el caso el Sr. Lapesa se sentía hondamente satisfecho de proporcionarlos ( $\mathrm{sic}$ ) esta utilidad, que no hubiera podido prestar si hábilmente no hubiera desempeñado el papel que le cupo representar al frente del Centro de Estudios Históricos en aquellos días difíciles.

De nada valieron estos testimonios concordes acerca de la obra humanitaria y de salvamento del patrimonio histórico desarrollada por el joven Rafael Lapesa en el «Centro de Estudios Históricos» madrileño. En la documentación que hemos podido leer se encuen- 
tra un escrito del Juzgado Superior de Revisiones de 13 de Abril de 1942, en el cual un juez de firma ilegible propone «a la Superioridad que procede denegar el recurso y confirmar la sanción que le fue impuesta al interesado por Orden de 12 de julio de 1940".

En fin el 31 de Octubre del mismo 1942 el Ministerio de Educación Nacional declara definitivamente revisado el expediente. Lapesa quedaba con su puesto de catedrático de enseñanza media en Oviedo, que había desempeñado interinamente en el Instituto «Calderón de la Barca» de Madrid, y luego como agregado al «Beatriz Galindo».

En sus recuerdos de 1979 don Rafael escribió estas palabras conmovedoras: «Movilizado nuevamente en 1938, dejé aquella especie de secretaria en manos del modelo de noble humanidad que fue don Benito Sánchez Alonso; pero seguí frecuentando el Centro cada vez más despoblado. Y confieso que deambulando por aquellos despachos y pasillos solitarios lloré más de una vez, convencido de que cualquiera que fuese la suerte de la contienda, el Centro y su espíritu no sobrevivirían ${ }^{8}$.

\section{Dámaso Alonso y la ACUÑaCión «GENERACIÓN DEL 27»}

La acuñación de la fórmula verbal generación del 27 tiene un proceso que se acelera en los años cincuenta del siglo Xx: de hecho la fórmula aparece ya al final de esos años en tanto designación estandarizada en algunos manuales de bachillerato. En el proceso don Dámaso tiene un papel determinante no porque emplee la fórmula propiamente dicha, sino porque estimula su creación.

Hay un texto de 1932 del entonces joven Dámaso Alonso en el que en efecto introduce expresiones de las que se derivaría la lexía: se trata de su artículo «Góngora y la Literatura Contemporánea», tipografiado con estas mayúsculas y en el que encontramos pasajes en los que habla de «la moderna generación literaria, los nuevos que en 1927 celebran el homenaje a Góngora», de «la nueva generación», etc., y en el que escribe por ej.: «Por primera vez en la historia de nuestra literatura, una generación entera ha rendido al poeta de las Soledades el tributo que se le debía. Nuestro centenario fué idea de Gerardo Diego. Las cartas de invitación a colaborar en él iban firmadas por J. Guillén, P. Salinas, D. Alonso, G. Diego, F. García Lorca y R. Alberti" (Boletín de la Biblioteca Menéndez Pelayo. Número extraordinario en Homenaje a D. Miguel Artigas, II, Santander, 1932, págs. 246-284).

Podemos comprobar cómo el joven Dámaso habla de celebraciones en 1927, y de una nueva y moderna «generación». Con Dámaso Alonso (y con un pequeño libro anterior de Valbuena) la fórmula estaba ya implícitamente dada, pues sólo faltó hacer una unidad léxica de las voces «generación» y « 27 ». No sabemos documentado que entonces se produjese tal paso.

Luego y de 1948 es el conocido artículo del propio don Dámaso «Una generación poética (1920-1936)», y en él no aparece tampoco la lexía «generación del 27», pero esa

" «Menéndez Pidal, creador...», p. 77, subrayado por nosotros. Cfr. todas las páginas que constituyen el cap. V («La guerra civil») de la obra ya mencionada de D. Catalán El archivo del romancero..., y en ellas la carta (por ej.) de Américo Castro a don Ramón de 18 de Marzo de 1937, en la que exclamaba: «Mis libros y papeles seguramente no los veré en la vida". 
lexía se obtiene del cruce de varios de sus pasajes. Don Dámaso habla de «la generación a que (como segundón) pertenezco», de «la generación poética anterior a nuestra guerra», etc., y además subraya el año 1927 y el acto público del Ateneo de Sevilla, y el culto a Góngora de entonces: Dámaso Alonso se refiere pues a una generación poética y a las circunstancias del año 27; aunque no lo escriba, da en realidad hecho el troquel generación del 27 (o del Veintisiete).

La autoridad de don Dámaso hizo que la expresión se generalizase y que la adoptasen filólogos vinculados a él, pero junto a nuestro autor la formulación quedó asimismo hecha por Juan Chabás, por el periodista Manuel de Val, por don Ángel Valbuena, y por José Luis Cano.

Por ej. la vez que más se detiene Juan Chabás en hablar de una generación del 27 es en su obra Literatura española contemporánea 1898-1950 (1952). En efecto en el capítulo XXIII de este amplio libro su autor se decide por emplear el troquel de «generación del 27 » repetidas veces, y recoge cómo se estimó en su momento que era «la revolución triunfante de la poesía española».

Del año 1953 es el artículo de Valbuena (aparecido en el Correo Literario que se editaba en Madrid) «La generación de 1927 vista al cabo de veinticinco años»: en tal texto se habla ciertamente de generación de 1927 tanto en el título como un par de veces en el cuerpo del escrito.

Manuel de Val hace un ensayo en Venezuela («Los poetas españoles del 27») en el mismo año 53, en el que no hace uso exactamente de la expresión, pero desde luego alude a «los poetas del 27» y a «aquella extraordinaria generación revolucionaria de poetas».

José Luis Cano, sensible catador de la lírica, puede comprobarse por igual que desde los años cincuenta hace uso asimismo de la lexía.

Etc. ${ }^{9}$.

Asimismo en el folleto Más testimonios sobre la lexía "generación del 27», Madrid, 2005.

- Damos datos sobre el troquel «generación del 27» en dos artículos del Homenaje en memoria de Fernando Lázaro Carreter (Univ. de Salamanca), y del Boletín de la Fundación Federico García Lorca (n. ${ }^{\circ} 37$ ). 